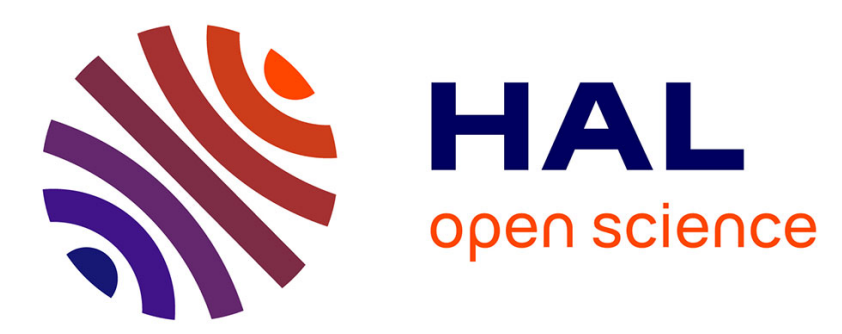

\title{
Rapid prediction of shrinkage and fibre saturation point on teak (Tectona grandis) wood based on near-infrared spectroscopy
}

\author{
Adzo-Dzifa Kokutse, Loïc Brancheriau, Gilles Chaix
}

\section{- To cite this version:}

Adzo-Dzifa Kokutse, Loïc Brancheriau, Gilles Chaix. Rapid prediction of shrinkage and fibre saturation point on teak (Tectona grandis) wood based on near-infrared spectroscopy. Annals of Forest Science, 2010, 67 (4), 10.1051/forest/2009123 . hal-00883570

\author{
HAL Id: hal-00883570 \\ https://hal.science/hal-00883570
}

Submitted on 1 Jan 2010

HAL is a multi-disciplinary open access archive for the deposit and dissemination of scientific research documents, whether they are published or not. The documents may come from teaching and research institutions in France or abroad, or from public or private research centers.
L'archive ouverte pluridisciplinaire HAL, est destinée au dépôt et à la diffusion de documents scientifiques de niveau recherche, publiés ou non, émanant des établissements d'enseignement et de recherche français ou étrangers, des laboratoires publics ou privés. 


\title{
Rapid prediction of shrinkage and fibre saturation point on teak (Tectona grandis) wood based on near-infrared spectroscopy
}

\author{
Adzo-Dzifa KoKUTSE ${ }^{1}$, Lö̈c BrANCHERIAU ${ }^{2}$, Gilles CHAIX ${ }^{3 *}$ \\ ${ }^{1}$ Laboratoire de Botanique et Ecologie Végétale, Faculté des Sciences, Université de Lomé, BP1515, Lomé, Togo \\ ${ }^{2}$ CIRAD, PERSYST Department, Production and Processing of Tropical Woods Unit, Montpellier, France \\ ${ }^{3}$ CIRAD, BIOS Department, Genetic Diversity and Breeding of Forest Species Unit, BP 5035, 34398 Montpellier Cedex 5, France
}

Keywords:

shrinkage /

fibre saturation point /

teak /

NIRS

(Received 14 April 2009; accepted 9 October 2009)

Mots-clés :

retrait /

point de saturation des fibres /

teck /

SPIR

\begin{abstract}
- Dimensional stability, along with the natural durability and colour of the wood, is one of the most important characteristics of teak used as timber. However, it is very time-consuming to take measurements of this kind. For the purposes of selection for the production of improved varieties, the number of samples to be measured rapidly exceeds the capacity of a traditional laboratory.

- Near-infrared spectroscopy, based on a set of reference data, is a tool enabling many of the chemical properties of wood to be predicted and the number of laboratory measurements to be reduced exponentially. The issue here is a question of checking the effectiveness of NIRS tool to build models and predict the shrinkage and fibre saturation point of teak wood from Togo.

- The results show the possible use of NIRS to measure the dimensional stability of teak wood and that it is appropriate to choose the type of wood and type of surface to be measured by NIRS. The best prediction models for radial and tangential shrinkage and fibre saturation point give $R^{2}$ values of $0.72,0.83$ and 0.87 respectively with ratios of performance deviation of $1.8,2.4$ and 2.8.

- Consequently, after verification on other sets of teak samples, which may or may not be included in the prediction model, NIRS can be used to predict shrinkage and fibre saturation point values accurately for a large number of samples, making it possible to include these characteristics in the selection criteria for classifying wood and high throughput phenotyping.
\end{abstract}

Résumé - Prédiction rapide du retrait et du point de saturation des fibres pour le bois de teck (Tectona grandis) par spectroscopie proche infrarouge.

- La stabilité dimensionnelle avec la durabilité naturelle et la couleur du bois, est l'une des plus importantes caractéristiques pour le teck utilisé en bois d'œuvre. Néanmoins, les mesures de ce caractère sont longues et coûteuses en temps. Pour les besoins de la sélection pour la production de variétés améliorées, le nombre d'échantillons à mesurer devient vite supérieur aux capacités d'un laboratoire traditionnel.

- La spectroscopie proche infrarouge, sur la base d'un jeu de données de références, est un outil qui permet de prédire de nombreuses propriétés chimiques du bois et de réduire le nombre de mesures de laboratoire de façon exponentielle. La question ici est de vérifier l'efficacité de l'outil NIRS pour construire des modèles et prédire les retraits et le point de saturation des fibres du bois de teck provenant de plantations du Togo.

- Les résultats démontrent la possible utilisation de la SPIR pour mesurer la stabilité dimensionnelle du bois de teck et qu'il a y lieu de choisir le type de bois et le type de face que l'on mesure par SPIR. Les modèles de prédiction pour les retraits radial et tangentiel et le point de saturation des fibres montrent des $R^{2}$ de $0,72,0,83,0,87$ respectivement avec des rapports d'efficacité de 1,8,2,4 et 2,8.

- En conséquence, et après vérification sur d'autres jeux d'échantillons de teck, qu'il conviendra ou non d'intégrer dans le modèle de prédiction, la SPIR permet de prédire des valeurs de retrait et de PSF avec efficacité pour un grand nombre d'échantillons rendant possible l'intégration de ces caractères dans les critères de sélection pour le classement des bois et pour le phénotypage à grande échelle.

\footnotetext{
* Corresponding author: gilles.chaix@ cirad.fr
} 


\section{INTRODUCTION}

Teak (Tectona grandis) has been selected for sustainable production of high quality timber in the tropics (Bhat and Priya, 2004). It is often used for outdoor purposes (e.g. boat decks, bridge building, and garden furniture) and traditional indoor uses such as parquet and furnishings. Its timber qualities include a golden brown colour with typical features and grain, resistance to fungus and termites. Teak wood possesses very interesting technological properties such as medium specific gravity, high strength (Bhat and Priya, 2004; Kokutse et al., 2004), good dimensional stability and high durability (Baillères and Durand, 2000). The main wood quality factors related to dimensional characteristics are shrinkages (tangential and radial) and sorption properties such as fibre saturation point $(F S P)$. Moisture can exist in wood as liquid water (free water) or water vapor in cell lumens and cavities, or as water held chemically (bound water) within cell walls. Conceptually, the moisture content at which only the cell walls are completely saturated (all water is bound) but no water exists in cell lumens is called the FSP. It is normally assumed that the FSP is the moisture content $(M C)$ below which the physical and mechanical properties of wood change as a function of moisture content (Berry and Roderich, 2005; Simpson and TenWold, 1999). FSP is affected by the presence of wood extractives, which can behave as hygroscopic, hydrophobic or neutral entities (Stamm, 1971). Teak has been reported as presenting shrinkage, from the green state to oven-dry condition, of 2.5 to $3.0 \%$ in the radial direction and 3.4 to $5.8 \%$ in the tangential direction (Simatupang and Yamamoto, 2000; Trokenbrodt and Josue, 1999). Several authors have shown the relationships between the presence of extracts in the heartwood, e.g. anthraquinones and tectoquinones, and teak wood durability (Haluk et al., 2001; Pahup et al., 1989; Simatupang and Yamamoto, 2000; Yamamoto et al., 1998). The good dimensional stability of teak wood is mainly due to the bulking effect of the ethanol and hot water soluble wood extractives located in the cell wall (Simatupang and Yamamoto, 2000). Some results have been published on the shrinkage of teak wood (Bhat, 1998; Sanwo, 1987; Simatupang and Yamamoto, 2000 ) but no studies have been carried out on FSP. Determination of shrinkage and FSP are based on tests that require destructive sampling and extensive sample preparation. The industry would benefit from employing a more rapid, nondestructive technique for the estimation of these properties.

An option for the estimation of these wood properties is near infrared (NIR) spectroscopy. This is based on vibrational spectroscopy that monitors changes in molecular vibrations intimately associated with changes in molecular structure. Spectra within the NIR region consist of overtone and combination bands of fundamental stretching vibrations of functional groups that occur in the middle infrared region, mainly $\mathrm{CH}$, $\mathrm{OH}$ and $\mathrm{NH}$, which represent the backbone of all biological compounds. The potential application of NIR spectroscopy to predict wood characteristics has been reported in the literature (Kelley et al., 2004; Tsuchikawa, 2007). It offers a rapid method for estimating many important wood properties including density, microfibril angle, stiffness (Cogdill et al.,
2004; Hein et al. 2009; Schimleck et al., 2005; 2007), and prediction of the longitudinal tensile modulus and strength (Hedrick et al., 2007). Gierlinger et al. (2003) have shown that NIR spectroscopy is an accurate and fast method for nondestructive determination of natural durability. The effect of biological deterioration on the physical, mechanical and chemical properties of wood has also been characterized through spectroscopy (Edwin and Ashraf, 2006). In the forest products industry, NIR spectroscopy is used mainly for rapid prediction of pulp yield and pulping characteristics (Alves et al., 2006; Boeriu et al., 2004; Brinkmann et al., 2002; Monrroy et al., 2008; Raymond et al., 2001; Schimleck and Michell, 1998; Schimleck et al., 1997; Wright et al., 1990). In addition, a few studies have used NIR spectroscopy to assess physical properties such as shrinkage (Baillères et al., 2002; Taylor et al., 2008). For studies concerning forest product, there is no reference in which NIR spectroscopy is used to assess characteristics such as FSP. This paper evaluates the potential of NIR spectroscopy for the assessment of some major physical wood characteristics for Teak. Our objective was to measure the prediction accuracy under actual operational conditions and to use the prediction model for selection according to non-destructive sampling methods of core samples.

\section{MATERIALS AND METHODS}

\subsection{Site description}

The study site was situated in the central part of Togo $\left(1^{\circ} 00^{\prime} \mathrm{E}\right.$, $\left.8^{\circ} 21^{\prime} \mathrm{N}\right)$, West Africa. This central area of Togo is covered by Guinean woody savannas and is situated at an altitude of $200-400 \mathrm{~m}$. In this area, two major seasons exist in a year, one long rainy season lasting 6-8 months, followed by a long dry season. Mean annual precipitation is $1400-1600 \mathrm{~mm}$ and temperatures vary from $25^{\circ} \mathrm{C}$ to $40{ }^{\circ} \mathrm{C}$ (Ern, 1979).

\subsection{Wood samples}

Twenty trees were selected for analysis from two plots, namely Tchorogo (established in 1972) and Oyou (established in 1966). The description of the study sites is presented in Table I. Planks were cut radially $(500 \mathrm{~mm}$ in the longitudinal axis and $50 \mathrm{~mm}$ in the tangential axis) between a height of 1 and $1.5 \mathrm{~m}$. Four beams were cut per plank along the diameter $(20 \times 20 \times 500 \mathrm{~mm})$ and lastly, 5 wood samples of dimensions $20 \times 20 \times 10 \mathrm{~mm}$ (in radial, tangential and longitudinal directions) were cut per beam. The samples were stabilized to a theoretical $M C$ of $12 \%$ in a climate chamber at $20{ }^{\circ} \mathrm{C}$ and $65 \%$ humidity. A total of 393 remaining samples were used for measuring dimensional stability, FSP and NIR absorbance. For each sample, 2 NIR measurements were recorded (longitudinal-radial (LR) and tangential-radial (TR) surfaces). All the samples were then ground into wood meal (with a $4 \mathrm{~mm}$ filter) to compare the prediction accuracy based on ground wood samples and solid wood samples.

\subsection{Determination of $F S P$}

FSP was obtained by measuring the weight and the dimensions of wood samples placed in different conditions of air temperature and 
Table I. Site characteristics. A: altitude (m); D: density (tree.ha $\left.{ }^{-1}\right) ; M D$ : mean diameter (cm) at height 1.3 m; $M H$ : mean height (m).

\begin{tabular}{lcccccc}
\hline Location & A & Year of plantation & Soil type & $D$ & $M D$ & $M H$ \\
\hline Tchorogo & 420 & 1972 & Ferruginous soil, sandy-silt structure & 2600 & $21.9 \pm 4.4$ & $16.1 \pm 1.7$ \\
Oyou & 420 & 1966 & Ferruginous soil clay, sandy-silt structure & 2600 & $23.4 \pm 3.1$ & $13.6 \pm 0.6$ \\
\hline
\end{tabular}

relative humidity (Ruelle et al., 2007). Initially, the samples were immersed in water until saturation. Next, each sample was oven dried in appropriate temperature and air humidity conditions, until the theoretical moisture content had reached $18 \%, 12 \%$ and $6 \%$ successively. When each state had been reached, all samples were weighed and the radial and tangential dimensions were then measured with a displacement transducer. Ink marks were printed on the samples to ensure correct repositioning between successive measurements. Finally, the samples were brought to the anhydrous state, by oven drying them at $103 \pm 2{ }^{\circ} \mathrm{C}$. The FSP is the constant coefficient (Eq. (2)) of the linear regression between the variation of transverse area (VTA, Eq. (1)) and the moisture content (MC) (Guitard, 1987):

$$
V T A=D R_{S A T} \cdot D T_{S A T}-D R_{M C} \cdot D T_{M C}
$$

with $D R$ : radial dimension, $D T$ : tangential dimension, $S A T$ : fully saturated sample and $M C$ : moisture content after conditioning $(18 \%$, $12 \%, 6 \%$ and $0 \%$ ).

$$
M C=b_{1} \cdot V T A+F S P+\varepsilon
$$

with $b_{1}$ : slope coefficient and $\varepsilon$ : random error.

\subsection{Measurement of shrinkages}

Radial shrinkage (RS) and tangential shrinkage (TS) were obtained using equation (3) between the saturation state and the final oven dried state:

$$
S=\frac{D_{S A T}-D_{0 \%}}{D_{S A T}}
$$

with $S$ : shrinkage, $D_{S A T}$ : saturated dimension, $D_{0 \%}$ : dried dimension.

\subsection{Near infrared spectra collection}

Near-infrared spectra were collected in the NIR region from 12500 to $3800 \mathrm{~cm}^{-1}$ (800-2 $850 \mathrm{~nm}$ ) on solid wood and ground wood with an NIR spectrometer (Bruker model Vector 22/NI) in diffuse reflectance mode at a spectral resolution of $8 \mathrm{~cm}^{-1}$ (each spectrum consisted of 2335 absorption values). Spectra taken from TR and LR surfaces of solid wood (sample used for dimensional stability) were used in the calibration modelling. Each spectrum was obtained with 32 scans, and means were calculated and compared to the standard in order to obtain the absorption spectrum of the sample. Wood meal spectra were also collected in diffuse reflectance mode using a spinning cup module. Each spectrum was obtained with 64 scans. Temperature and relative humidity were kept constant $\left(20{ }^{\circ} \mathrm{C}, 65 \%\right.$ respectively) throughout the NIR processing.

\subsection{Data processing}

In a first step, a validation set was established by a selection of 100 samples among the 393 samples based on the sample distances calculated on five components after a principal component analysis (PCA) of the spectral data. We assumed that these covered the FSP and shrinkage ranges. In a second step, the spectra data from 293 remaining samples were regressed against the FSP, TS and RS, and by means of 5 random cross validation groups, a significant number of Partial Least Squares (PLS) components (rank) was obtained using OPUS Quant 2 software (Bruker) and Unscrambler 9.8 (Camo). This step allowed the pre-processing to be compared and outliers to be detected. Different data treatments were evaluated for the spectral data: first derivative (D1), second derivative (D2), standard normal variate (SNV), detrend (DT), and combinations of all. SNV is a transformation usually applied to spectroscopic data, which centers and scales each individual spectrum (i.e. a sample-oriented standardization). DT is a transformation which seeks to remove non-linear trends in spectroscopic data. Like SNV, it is applied to individual spectra. DT and SNV are often used in combination to reduce multi-collinearity, baseline shift and curvature in spectroscopic data. Derivatives of spectral data are used to remove or suppress low-frequency background noise and global-line variations. Derivatives also provide a resolution enhancement that helps to identify weak peaks that are not apparent in the original spectrum. The PLS models were then used to predict data of the validation set, evaluating their predictive ability. The number of outsiders (samples whose predicted value lies outside the calibration range) and the number of outliers (samples whose Mahalanobis distance is too large, meaning that the similarity of the spectra compared to the calibration spectra is too low) of the models were compared. The quality and the final selection of the models were assessed by: coefficient of determination $\left(R^{2}\right)$ from reference values and predicted values by the models, standard error of calibration $(S E C)$ and standard error of cross-validation $(S E C V)$. The best results for each pre-treatment considering either the minimum $S E C$ or $S E C V$ were noted. When the best models were determined, a validation set (established by random selection from within the batch and not used for the calibration process) was used to test their performances. The performance of models was controlled by the coefficient of determination $\left(R^{2}\right)$ from reference values and predicted values obtained by the models and the standard error of prediction (SEP, Eq. (4)).

$$
S E P=\sqrt{\frac{\sum_{p=1}^{n}\left(\hat{y}_{p}-y_{p}\right)^{2}}{n}}
$$

with $\hat{y}_{p}$ : estimated value, $y_{p}$ : measured value, $n$ : number of samples in the validation set.

Models were tested by the Ratio of Performance Deviation (RPD) which is the ratio of the standard error $S D$ (deviation for the reference method values) of sample validation divided by $S E P$.

\section{RESULTS}

\subsection{Solid wood calibration}

The FSP of the 393 samples ranged from $16.2 \%$ to $26.0 \%$ with an average of $20.4 \%$ and a standard deviation of $1.8 \%$ 
Table II. Number of samples $(N)$ and descriptive statistics of reference values. $M$ : mean $(\%)$. S D: standard deviation (\%). $C V:$ coefficient of variation (\%). Min: minimum value (\%). Max: maximum value $(\%)$.

\begin{tabular}{lcccccc}
\hline Properties & $N$ & $M$ & $S D$ & $C V$ & Min & Max \\
\hline Radial shrinkage & 393 & 3.2 & 0.7 & 21.9 & 1.7 & 5.4 \\
Tangential shrinkage & 393 & 5.5 & 1.3 & 23.6 & 2.3 & 9.3 \\
Fibre saturation point & 393 & 20.4 & 1.8 & 8.8 & 16.2 & 26 \\
\hline
\end{tabular}

Table III. Solid wood - PLS results of the calibration and cross-validation on detrend, SNV (standard normal variate) and derivate 2 preprocessing spectral data. $N$ : number of sample. $M$ : mean. $S D$ : standard deviation. $S E C$ : standard error of calibration. $S E C V$ : standard error of cross validation.

\begin{tabular}{lccccccccc}
\hline NIR surface & Properties & $N$ & Outliers & $M$ & $S D$ & Rank & SEC & SECV & $r^{2}$ \\
\hline \multirow{3}{*}{ LR } & Radial shrinkage & 293 & 10 & 3.1 & 0.68 & 4 & 0.35 & 0.39 & 0.74 \\
& Tangential shrinkage & 293 & 10 & 5.5 & 1.24 & 4 & 0.52 & 0.59 & 0.83 \\
& Fibre saturation point & 293 & 14 & 20.3 & 1.68 & 4 & 0.65 & 0.74 & 0.85 \\
\hline \multirow{3}{*}{ TR } & Radial shrinkage & 293 & 10 & 3.1 & 0.7 & 5 & 0.26 & 0.30 & 0.86 \\
& Tangential shrinkage & 293 & 12 & 5.5 & 1.23 & 5 & 0.43 & 0.48 & 0.88 \\
& Fibre saturation point & 293 & 23 & 20.4 & 1.68 & 5 & 0.53 & 0.58 & 0.90 \\
\hline
\end{tabular}

(Tab. II). For all samples, the radial and tangential shrinkages varied from $1.7 \%$ to $5.4 \%$ and from $2.3 \%$ to $9.3 \%$ respectively, with a standard deviation of 0.7 and 1.3 (Tab. II). Shrinkage properties are more variable than the FSP. The coefficient of variation for radial and tangential shrinkage is $22 \%$ and $24 \%$ compared to $9 \%$ for the FSP. This reading is not due to measurement error as the error relating to shrinkage $(1.6 \%$ error for RS and $0.9 \%$ for TS) is smaller than that for FSP (7.6\%). The measurement error calculations are detailed in the annex. In the absence of other considerations, high variability and low measurement error favour the statistical estimation of shrinkage variables with respect to the $F S P$ variable.

The calibration results for solid wood are given in Table III. Whatever the estimated property and the transverse section, the best pretreatment is detrend followed by SNV and D2. All the models are highly significant with determination coefficients greater or equal to 0.74 . The models calculated on the TR surface absorbance perform better than the model based on LR surface. The $r^{2}$ are systematically higher (1 significant latent value higher for TR surface). In addition, the TS models are better than the RS models, irrespective of the TR surface under consideration. The laboratory standard deviation (SEL of 0.53 calculated in the annex) is very close to the calibration standard deviation (SEC of 0.65 and 0.53 ) for the FSP. Of the three properties studied, the FSP is the best estimated $\left(r^{2}=0.90\right.$ for the TR surface). With respect to the shrinkage properties, the $S E C$ is 10 times higher than the SEL which is equal to approximately 0.026 (SEL estimated in the annex).

\subsection{Solid wood validation}

The validation results for solid wood are shown in Figure 1 and Table IV. The population used to validate the models has statistical characteristics similar to those of the calibration population, irrespective of the property being studied (Tab. IV). The variability percentages explained by the validation models are lower than those for calibration but the dif- ference is slight (from 1-3 points for FSP, to 7-14 points for RS). The findings for calibration are also found in the validation population; i.e. (a) the models for the TR surface are higher than the models on the LR surface, (b) the TS models are better than the RS models, (c) FSP is the property with the best estimation. The value found for the RPD to FSP shows that this model may be used for rough screening according to the reference gave by Williams and Sobering (1993).

\subsection{Wood meal calibration}

Table V and Figure 2 show wood meal calibration and cross-validation results. As for solid wood (Tab. III), the best pretreatment obtained is D2 followed by SNV and detrend. The ranks relating to the models for powders are lower than those relating to solid woods. The variability percentages explained by the powder samples are lower than those obtained for solid woods. As with solid wood, the estimation for tangential shrinkage is better than for radial shrinkage. FSP is the best estimated property, with an $r^{2}$ very close to that obtained for solid wood (Tab. III).

An additional analysis was then conducted using the models for powders on solids and vice versa. The findings cannot be used when the "solid" models are used for powders and if the "powder" model is used on the TR section of solids. However, if the "powder" model is used to predict data from the spectra measured on the LR section of solid samples, results that can be used with an $r^{2}$ of 0.81 for the FSP and a RPD of 2.3 is obtained (Tab. VI).

\section{DISCUSSION}

The findings show that, in the case of solid wood, the models developed for the TR section are better than the models developed for the LR section (Tabs. III and IV). It is thought that this observation may be explained, firstly by the fact that 

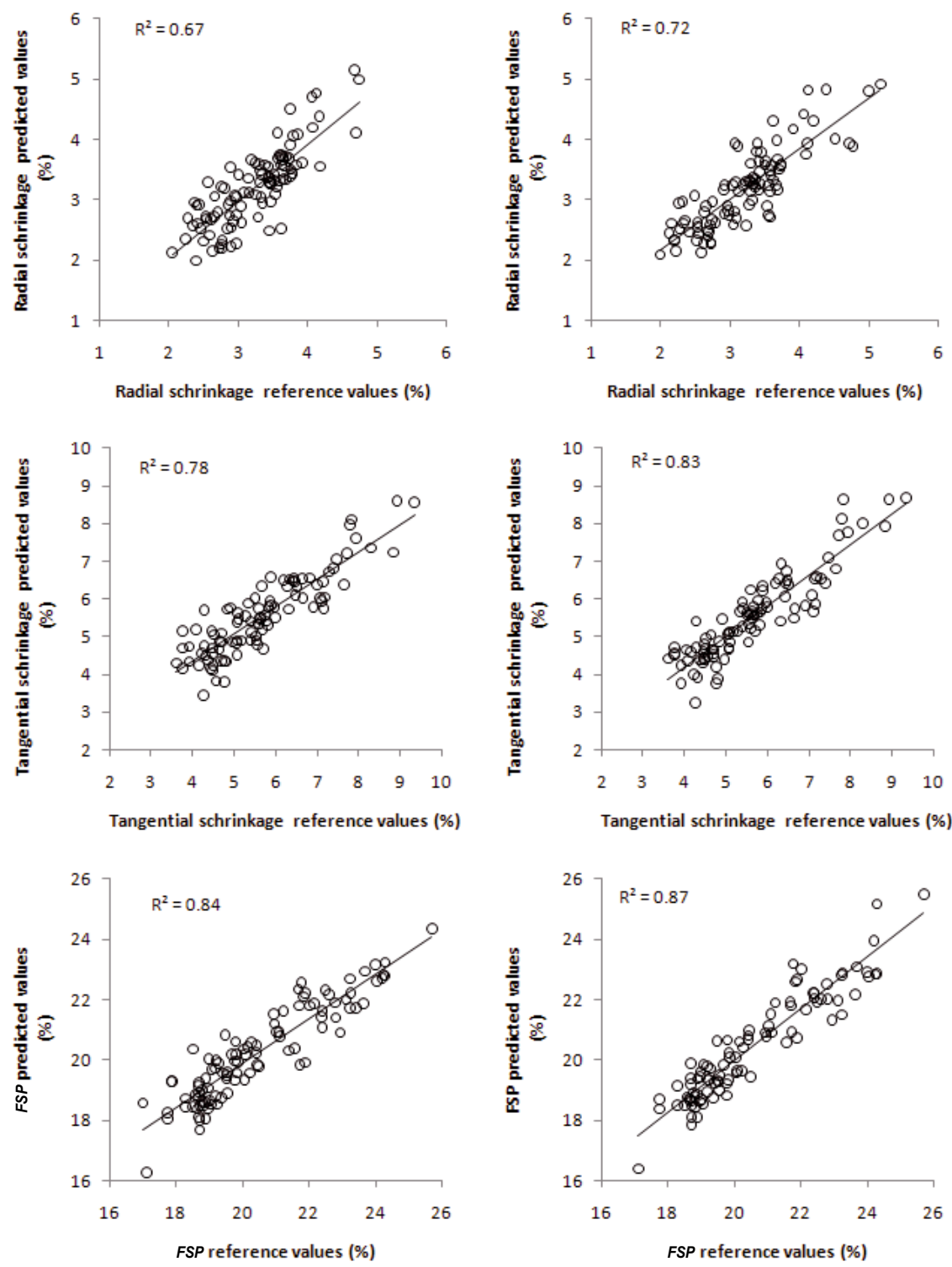

A

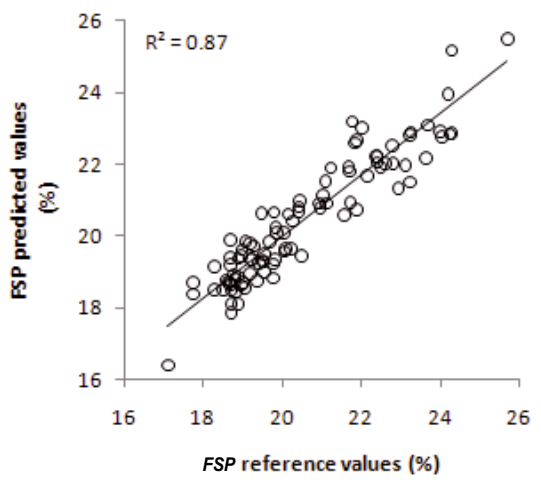

B

Figure 1. Near Infrared - Partial Least Square predicted versus laboratory determined radial shrinkage, tangential shrinkage and fibre saturation point for Tectona grandis solid woods (A: NIR data from Longitudinal-Radial surface, B: NIR data from Tangential-Radial surface).

Table IV. Solid wood - PLS Model results of test validation. $N$ : number of sample. $M$ : mean. $S D$ : standard deviation. SEP: standard error of prediction. $R P D$ : ratio performance to deviation.

\begin{tabular}{lcccccccc}
\hline NIR surface & Properties & $N$ & Outliers & $M$ & $S D$ & $S E P$ & $r^{2}$ & $R P D$ \\
\hline \multirow{3}{*}{ LR } & Radial shrinkage & 100 & 1 & 3.21 & 0.65 & 0.37 & 0.67 & 1.8 \\
& Tangential shrinkage & 100 & 3 & 5.68 & 1.27 & 0.60 & 0.78 & 2.1 \\
& Fibre saturation point & 100 & 0 & 20.48 & 1.95 & 0.84 & 0.84 & 2.3 \\
\hline \multirow{3}{*}{ TR } & Radial shrinkage & 100 & 3 & 3.21 & 0.65 & 0.36 & 0.72 & 1.8 \\
& Tangential shrinkage & 100 & 4 & 5.64 & 1.27 & 0.52 & 0.83 & 2.4 \\
& Fibre saturation point & 100 & 5 & 20.58 & 1.91 & 0.68 & 0.87 & 2.8 \\
\hline
\end{tabular}


Table V. Powder samples - PLS results of the calibration and cross-validation on detrend, SNV (standard normal variate) and derivate 2 preprocessing spectral data. $N$ : number of sample. $M$ : mean. $S D$ : standard deviation. SEC: standard error of calibration. SECV: standard error of cross validation.

\begin{tabular}{lcccccccc}
\hline Properties & $N$ & Outliers & $M$ & $S D$ & Rank & SEC & SECV & $r^{2}$ \\
\hline Radial shrinkage & 79 & 2 & 3.16 & 0.66 & 3 & 0.35 & 0.42 & 0.71 \\
Tangential shrinkage & 79 & 2 & 5.47 & 1.27 & 2 & 0.61 & 0.73 & 0.77 \\
Fibre saturation point & 79 & 3 & 20.35 & 1.67 & 3 & 0.62 & 0.78 & 0.87 \\
\hline
\end{tabular}
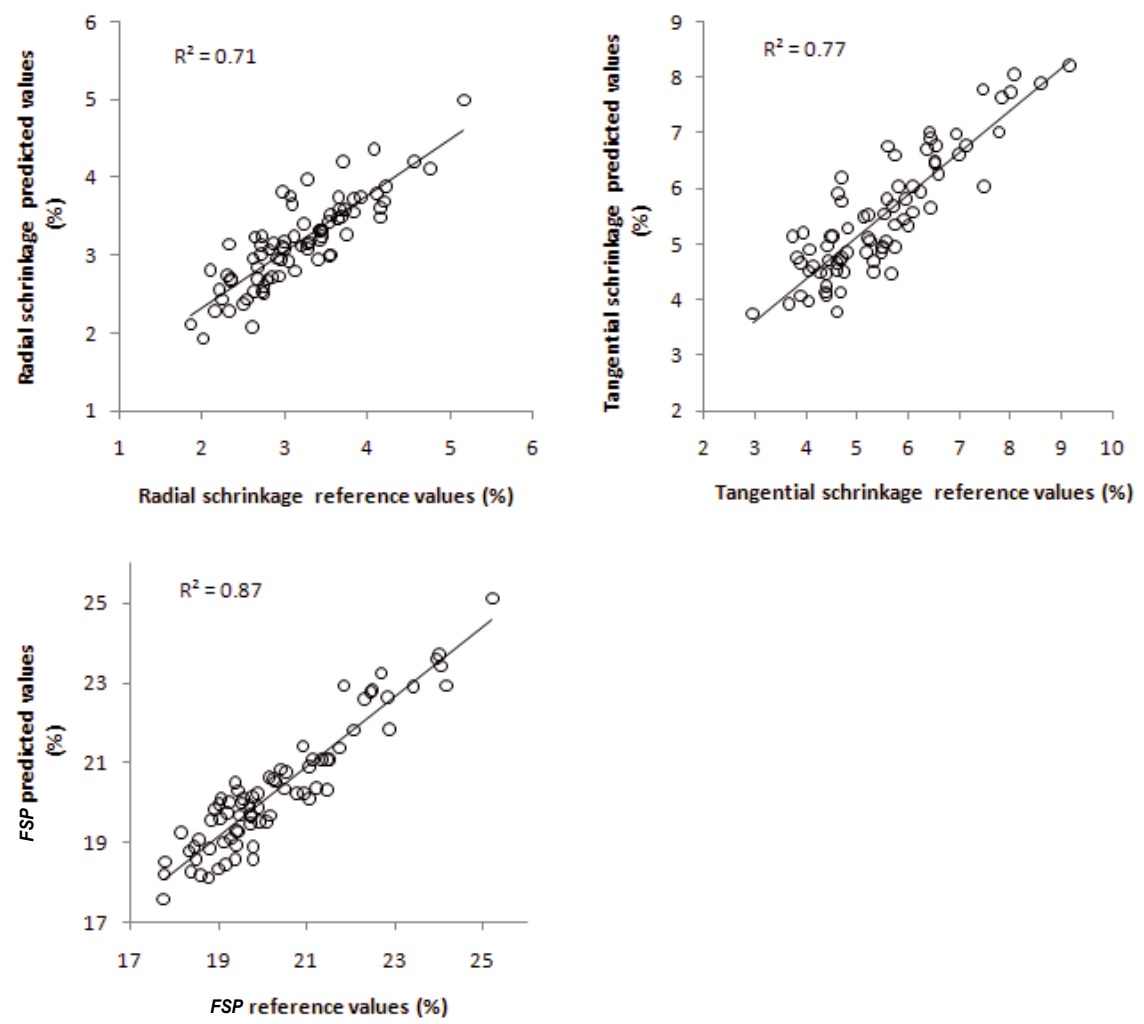

Figure 2. Near Infrared - Partial Least Square predicted versus laboratory determined radial shrinkage, tangential shrinkage and fibre saturation point for Tectona grandis ground wood.

Table VI. Models developed for powders and used for prediction purposes on the Longitudinal-Radial surface spectra of solid samples. $N$ : number of sample. $M$ : mean. $S D$ : standard deviation. $S E P$ : standard error of prediction. $R P D$ : ratio performance to deviation.

\begin{tabular}{lccccccc}
\hline Properties & $N$ & Outliers & Means & $S D$ & $S E P$ & $r^{2}$ & $R P D$ \\
\hline Radial shrinkage & 393 & 11 & 3.14 & 0.68 & 0.43 & 0.63 & 1.6 \\
Tangential shrinkage & 393 & 19 & 5.57 & 1.24 & 0.77 & 0.72 & 1.6 \\
Fibre saturation point & 393 & 19 & 20.37 & 1.77 & 0.78 & 0.81 & 2.3 \\
\hline
\end{tabular}

the width of the LR surface of the sample corresponds to the dimension of the infrared beam $(10 \mathrm{~mm})$. Operational errors in positioning the samples may therefore have added noise to the experiment measurements. Furthermore, the infrared beam touches all the anatomical elements directly on the TR surface while the same elements are measured by diffuse reflection inside the material in the LR surface.
With respect to the shrinkage properties, the TS models are systematically better than the RS models (Tabs. III-V). This phenomenon is explained by the fact that the measurement error for TS $(0.9 \%$, see annex) is lower than the RS measurement error $(1.6 \%$, see annex). It is also thought that there is an operational effect, the measurements were always taken in the same order: tangential then radial. It is possible therefore that 
additional humidity between the two measurements may have affected the radial measurements.

Of the three properties studied for solid samples and powders, FSP is the best-estimated property (Tabs. III-V). However, there is a higher measurement error for $F S P(7.6 \%)$ than for tangential and radial shrinkages and a lower variability (coefficient of variation of 9\%) than for TS and RS (variation coefficients of $24 \%$ for TS and $22 \%$ for RS). The number of anomalies detected (outliers) is always higher for FSP than for shrinkages. This finding does not appear to be sufficient to explain the fact that the FSP is the best estimated by the models. It would appear to be due to the way in which the FSP is calculated: the surface variation calculation takes into account the radial and tangential dimensions, the use of linear adjustment also tends to reduce experimental error (the laboratory errors calculated in the annex are maximum theoretical errors).

The ranks relating to the models for powders (rank 2 and 3 models, Tab. V) are lower than those relating to solid woods (rank 4 and 5 models, Tab. III). This finding shows that the information necessary for estimating the properties is more condensed in the case of powders. It is thought that the measurement noise due to structural heterogeneity and irregularities on the surface of the solid wood is lessened in the case of powders. In this form the material is homogenised with respect to the measurement surface (dimension of the ground particles: $4 \mathrm{~mm}$; dimension of the measurement beam: $10 \mathrm{~mm}$ ). During the measurement of powders the range recorded for each sample is the average of several scans which, if a spinning cup is used for measurement, includes a larger exchange volume between the beam and the material. Consequently, the information found on the powders is certainly more complete than that obtained for solid woods.

The models developed for powders may be used only on the LR surface of solid woods (Tab. VI). This phenomenon can be explained by the mathematical distances being very short between the powder ranges and the solid wood ranges for the LR surface. It can therefore be presumed that the data within these ranges is similar. It is thought that this phenomenon may be explained purely by the grinding: the grade of grinding used and the structure of the material favours the formation of powder in the form of flakes, the larger axis of which coincides with the lengthwise axis of the solid wood.

The statistical models obtained by NIRS calibration demonstrate highly significant levels of correlation between the predicted values and the reference values. The differences of absorption of the near infrared rays depend on the nature and concentration of the chemical components of the material (Hein et al., 2009). In the case of the water/wood material relationship and its consequences on dimensional variations, the bound water (which defines the FSP) is absorbed on the surface of the cell cavities in polymolecular layers and in the internal walls of the ligneous matter at the polysaccharides hydroxy sites. To reach the hydrogen bridge sites, some of the water molecules enter the cell wall with a definite propensity for hemicelluloses causing dimensional variations or shrinkage (Guitard, 1987). The FSP may also be affected by the extractives (Arevalo Fuentes, 2002; Brémaud, 2006; Chafe, 1987; Hernandez, 2007). The anatomy of the material does not however appear to play a determining role in adsorption (Hernandez, 2007).

\section{CONCLUSION}

The findings of this study demonstrate the possible use of NIRS to measure the dimensional stability of teak wood. The precision of the models developed is slightly lower than the reference measurement but its value and the rapidity of measurement undisputedly show advantages for this approach. In accordance with the reference list commonly adopted, the $R P D$ values obtained after validation for the best prediction models, whether from ranges of solid woods or powders, are sufficient for screening for shrinkages and an approximate prediction of FSP.

These models remain to be tested on other samples of different origins and ages. The inclusion of additional samples other than those studied will lead to stronger prediction models which may be used on a wide range of woods of different plantation origins and enable a shift away from traditional shrinkage measurements on large sets of samples requiring measurement capacities which go well beyond the possibilities of a reference laboratory, particularly in the case of genetic studies which require high-throughput phenotyping. Nevertheless, this will always be necessary for developing existing equations and conducting regular controls.

Additional studies will be conducted on the variability of extractives in teak wood samples. There is no doubt that comparing the results presented here with future results will give matter for discussion on controlling the dimensional stability of teak wood when drying.

\section{ANNEX - SEL ESTIMATION}

\section{Definition of relative uncertainty and SEL estimation}

Relative uncertainty (RU) is the ratio of the absolute uncertainty $(|\Delta X|)$ of a measurement to the best estimate (mean of $X$ ). It expresses the relative size of the uncertainty of a measurement (its precision):

$$
R U(X)=\frac{|\Delta X|}{\bar{X}}
$$

Assuming a normal distribution of the measurement error, the standard error of laboratory $(S E L)$ can thus be estimated as (with a confidence level of 95\%):

$$
S E L(X) \approx 0.51 \bar{X} \cdot R U(X) .
$$

\section{Uncertainty of shrinkage computation}

Using (Eq. (3)) and (Eq. (5)), the relative uncertainty can be written as:

$$
R U(S)=\left(\frac{1}{\overline{D_{S A T}}}+\frac{2}{\overline{D_{S A T}-D_{0 \%}}}\right)|\Delta D| .
$$


The absolute uncertainty $|\Delta D|$ is equal to $0.005 \mathrm{~mm}$, the mean value of $D_{S A T}$ is $20.21 \mathrm{~mm}$ for radial measurements and is equal to $20.50 \mathrm{~mm}$ for tangential measurements. The mean of the dimension difference is $0.64 \mathrm{~mm}$ ( $R$ axis) and is $1.13 \mathrm{~mm}$ ( $T$ axis). Using Equation (7), the $S$ uncertainty values are thus equal to:

$$
\begin{aligned}
& R U(R S)=1.6 \% \\
& R U(T S)=0.9 \%
\end{aligned} \text { with } \begin{aligned}
& S E L(R S)=0.026 \% \\
& S E L(T S)=0.026 \%
\end{aligned}
$$

\section{Uncertainty of moisture content computation}

Moisture content of wood $(M C)$ is assessed using the formula:

$$
M C=\frac{W_{H}-W_{0}}{W_{0}} .
$$

With $W_{H}$ : weight of the sample, $W_{0}$ : weight of the oven-dry sample. From Equation (5) and Equation (9), the relative uncertainty can be expressed as follows:

$$
R U(M C)=\left(\frac{1}{\overline{W_{0}}}+\frac{2}{\overline{W_{H}-W_{0}}}\right)|\Delta W| .
$$

The absolute uncertainty $|\Delta W|$ is equal to $0.005 \mathrm{~g}$, the mean weight of the oven-dry samples is $3.00 \mathrm{~g}$ and the mean of the weight difference is $0.40 \mathrm{~g}$. Using Equation (10), the $M C$ uncertainty value is thus equal to:

$$
R U(M C)=2.7 \% \text {. }
$$

\section{Uncertainty of area computation}

The variation of transverse area (VTA) between full saturation and given $M C$ is written below:

$$
V T A=D R_{S A T} \cdot D T_{S A T}-D R_{M C} \cdot D T_{M C} .
$$

With $D R$ : radial dimension, $D T$ : tangential dimension,_SAT: fully saturated sample and _ $M C$ : moisture content after conditioning. From Equation (5) and Equation (12), the relative uncertainty can be expressed as follows:

$$
\begin{aligned}
R U(V T A)= & \frac{R U\left(D R_{S A T} \cdot D T_{S A T}\right) \overline{D R_{S A T} \cdot D T_{S A T}}}{\overline{V T A}} \\
& +\frac{R U\left(D R_{M C} \cdot D T_{M C}\right) \overline{D R_{M C} \cdot D T_{M C}}}{\overline{V T A}} .
\end{aligned}
$$

Equation (13) can be simplified assuming the equality between radial and tangential dimensions ( $D$ in Eq. (14)) and also small values of transverse shrinkages:

$$
R U(V T A)=\frac{4 \bar{D}|\Delta D|}{\overline{V T A}} .
$$

The measurement error $|\Delta D|$ is $0.005 \mathrm{~mm}$, the dimension $D$ is set to $20 \mathrm{~mm}$ and the mean value of $V T A$ is closed to $40 \mathrm{~mm}^{2}$. The VTA uncertainty is thus equal to:

$$
R U(V T A)=1 \% \text {. }
$$

\section{Uncertainty of FSP determination}

- The FSP corresponds to the constant coefficient of the linear regression equation between $V T A$ and $M C$ :

$$
M C=b_{1} \cdot V T A+F S P+\varepsilon
$$

with $b_{1}$ : slope coefficient and $e$ : random error. From equation (16), the SEL associated to FSP is the standard deviation of the constant coefficient estimation. SEL can be computed if the relationship between the uncertainties (VTA and $M C$ ) and $\varepsilon$ is known.

- The question can be expressed as: assuming a perfect linear relationship between two variables $X$ and $Y: Y=$ $b_{1} \cdot X+b_{0}$. If perturbations are added in $X$ and $Y$, what will the corresponding error $\varepsilon$ be?

A perturbation of $X$ can be written as: $X^{*}=X+\varepsilon_{X}$. The error $\varepsilon_{X}$ is assumed to be a random variable normally distributed with mean 0 and variance $\sigma^{2}\left(\varepsilon_{X}\right)$. The link between $|\Delta X|$ and $\varepsilon_{X}$ is $|\Delta X| \approx 1.96 \sigma\left(\varepsilon_{X}\right)$ (with a confidence level of $95 \%$ ). The residual sum of squares $(R S S)$ is defined as:

$$
\begin{aligned}
& R S S=\sum_{p=1}^{n}\left(Y_{p}^{*}-b_{1} X_{p}^{*}-b_{0}\right)^{2} \\
&=\sum_{p=1}^{n}\left(Y_{p}+\varepsilon_{Y p}-b_{1} X_{p}-b_{1} \varepsilon_{X p}-b_{0}\right)^{2} \\
&=\sigma^{2}(U \varepsilon) \sum_{p=1}^{n}\left(\frac{U \varepsilon_{p}}{\sigma(U \varepsilon)}\right)^{2}
\end{aligned}
$$

with $U \varepsilon_{p}=\varepsilon_{Y p}-b_{1} \varepsilon_{X p}$ and $\sigma^{2}(U \varepsilon)=\sigma^{2}\left(\varepsilon_{Y}\right)+b_{1}^{2} \sigma^{2}\left(\varepsilon_{X}\right)$. The variable $U \varepsilon$ (Eq. (17)) is normally distributed with a mean 0 and a variance $\sigma^{2}(U \varepsilon)$. The sum of equation (17) thus follows a chi-square distribution with a degree of freedom equal to $v=n-1$. The upper bound of RSS corresponds to the $p$ percentile of the chi-square distribution (confidence level of $95 \%)$ :

$$
R S S=\left[\left(\frac{R U(Y) \bar{Y}}{1.96}\right)^{2}+b_{1}^{2}\left(\frac{R U(X) \bar{X}}{1.96}\right)^{2}\right] \chi_{0.95}^{2}(n-1)
$$

with $\chi^{2}$ : chi-square cumulative distribution function. The classic Equation (19) is finally used with (18) to assess the residual standard error:

$$
\sigma(\varepsilon)=\sqrt{\frac{R S S}{n-2}} .
$$

- From Equations (16), (18) and (19), the SEL associated to FSP can be determined as follows:

$$
\begin{gathered}
S E L_{F S P}=\sqrt{\frac{\frac{1}{n}+\frac{{\overline{X_{p}+\varepsilon_{X p}}}^{2}}{\sum_{p=1}^{n}\left(X_{p}+\varepsilon_{X p}-\overline{X_{p}+\varepsilon_{X p}}\right)^{2}} \sigma(\varepsilon)}{\approx}} \\
\approx \sqrt{\frac{1}{n}+\frac{\bar{X}_{p}^{2}}{\sum_{p=1}^{n}\left(X_{p}-\overline{X_{p}}\right)^{2}}} \sigma(\varepsilon) .
\end{gathered}
$$


The relative uncertainty associated to $F S P$ computation is (confidence level of 95\%):

$$
R U(F S P)=\frac{t_{0.975}(n-2) S E L_{F S P}}{\overline{F S P}}
$$

with $t$ : student cumulative distribution function.

- The data set used for numerical application is VTA $\{24$; $36 ; 48 ; 60\}$ associated with $M C\{18 ; 12 ; 6 ; 0\}$. The relationship between VTA and $M C$ is strictly linear with coefficients $b_{1}\{-0.5\}$ and $b_{0}\{30\}$. This example represents the ideal case of FSP determination.

Equations (20) and (21) are used with (11) and (15). The results are shown below:

$$
\begin{aligned}
& R S S=0.21 \\
& \sigma(\varepsilon)=0.32 \\
& S E L(F S P)=0.53 \\
& R U(F S P)=7.6 \% .
\end{aligned}
$$

Acknowledgements: Thanks due to the International Foundation of Science (IFS), Sweden, and to the Agence Universitaire de la Francophonie for funding our research on teak plantation in Togo.

\section{REFERENCES}

Alves A., Schwanninger M., Pereira H., and Rodrigues J., 2006. Calibration of NIR to assess lignin composition (H/G ratio) in maritime pine wood using analytical pyrolysis as the reference method, Holzforschung 60: 29-31.

Arevalo Fuentes R.L., 2002. Influence des composantes secondaires et de la structure anatomique sur les propriétés physico-mécaniques du bois d'Acajou (Swietenia macrophylla King). Ph.D., Département des sciences du bois et de la forêt/ Faculté de foresterie et de géomatique, Université Laval, Québec, 145 p.

Baillères H. and Durand P., 2000. Non-destructive techniques for wood quality assessment of plantation-grown teak. Bois et Forêts des Tropiques 263: 17-29.

Baillères H., Davrieux F., and Ham-Pichavant F., 2002. Near infrared analysis as a tool for rapid screening of some major wood characteristics in a eucalyptus breeding programme. Ann. For. Sci. 59: 479490.

Berry L.S. and Roderick L.M., 2005. Plant-water relations and the fibre saturation point. New Phytol. 168: 25-37.

Bhat K.M., 1998. Properties of fast-grown teakwood: impact on endusers' requirements. J. Trop. For. Prod. 4: 1-10.

Bhat K.M. and Priya P.B., 2004. Influence of provenance variation on wood properties of teak from the western Ghat region in India. IAWA J. 25: 273-282.

Boeriu G.C., Bravo D., Gosselink R.J.A., and Van Dam J.E.G., 2004. Characterisation of structure-dependent functional properties of lignin with infrared spectroscopy. Ind. Crops Prod. 20: 205-218.

Brémaud I., 2006. Diversité des bois utilisés ou utilisables en facture d'instruments de musique. Ph.D. thesis in Mechanics, Univ. Montpellier II, 294 p.

Brinkmann K., Blaschke L., and Polle A., 2002. Comparison of different methods for lignin determination as a basis for calibration of nearinfrared reflectance spectroscopy and implications of lignoproteins. J. Chem. Ecol. 28: 2483-2500.
Chafe C., 1987. Collapse, volumetric shrinkage, specific gravity and extractives in Eucalyptus and others species. Part II: The influence of wood extractives. Wood Sci. Technol. 21: 27-41.

Cogdill R.P., Schimleck L.R., Jones P.D., Peter G.F., Daniels R.F., and Clark A., 2004. Estimation of the physical wood properties of Pinus taeda L. Radial strips using least squares support vector machines. J. Near Infrared Spec. 12: 263-269.

Edwin L. and Ashraf M.P., 2006. Assessment of biodeterioration of rubber wood exposed to field conditions. Int. Biodeter. Biodegr. 57: 31-36.

Ern H., 1979. Die Vegetation Togo. Gliederrung, Gefährdung, Erhaltung. Willdenowia. 9: 295-312.

Guitard D., 1987. Mécanique du matériau bois et composites. Cépaduès, $238 \mathrm{p}$.

Gierlinger N., Jacques D., Schwanninger M., Wimmer R., Hinterstoisser B., and Paques L.E., 2003. Rapid predictions of natural durability of larch heartwood using Fourier transform near-infrared spectroscopy. Can. J. For. Res. 33: 1727-1736.

Haluk J.P., Roussel C., and Thévénon M.F., 2001. Importance des quinones dans les propriétés antifongiques du Teck (Tectona grandis). Les cahiers Scientifiques du Bois 2: 77-83.

Hedrick E.S., Bennett M.R., Asce M., Rials T.G., and Kelley S.S., 2007. Correlation of near-infrared spectroscopy measurements with the properties of treated wood. J. Mater. Civil Eng. 19: 279-285.

Hein G.P.R., Lima J.L., and Chaix G., 2009. Robustness of models based on near infrared spectra to predict the basic density in Eucalyptus urophylla wood. J. Near Infrared Spec. 17: 141-150.

Hernandez R.E., 2007. Effects of extraneous substances, wood density and interlocked grain on fiber saturation point of hardwoods. Wood Mat. Sci. Eng. 2: 45-53.

Kelley S.S., Rials T.G., Snell R., Groom L.H., and Sluiter A.D., 2004. Use of near- infrared spectroscopy to measure the chemical and mechanical properties of solid wood. Wood Sci. Technol. 38: 257-276.

Kokutse A.D., Baillères H., Stokes A., and Kokou K., 2004. Proportion and quality of heartwood in Togolese teak (Tectona grandis L.f). For. Ecol. Manage. 189: 37-48.

Monrroy M., Mendonça R., Baeza J., Ruiz J., Ferraz A., and Freer J., 2008. Estimation of hexenuronic acids and kappa number in kraft pulps of Eucalyptus globulus by Fourier transform near infrared spectroscopy and multivariate analysis. J. Near Infrared Spec. 16: $121-128$.

Pahup S., Sunita J., and Sangeeta B., 1989. A 1, 4-Anthraquinone derivate from Tectona grandis. Phytochemistry 28: 1258-1259.

Raymond C.A., Schimleck L.R., Muneri A., and Michell A.J., 2001. Nondestructive sampling of Eucalyptus globulus and E. nitens for wood properties. III. Predicted pulp yield using near infrared reflectance analysis. Wood Sci. Technol. 35: 203-215.

Ruelle J., Beauchene J., Thibaut A., and Thibaut B., 2007. Comparison of physical and mechanical properties of tension and opposite wood from ten tropical rainforest trees from different species. Ann. For. Sci. 64: 503-510.

Sanwo S.K., 1987. The characteristics of the crown-formed and stemformed wood in plantation Grown teak (Tectona grandis L.f) in Nigeria. J. Inst. Wood Sci. 11: 85-88.

Schimleck L.R., Wright P.J., Michell A.J., and Wallis A.F.A., 1997. Nearinfrared spectra and chemical composition of Eucalyptus globulus and E. nitens plantation woods. Appita J. 50: 40-45.

Schimleck L.R. and Michell A.J., 1998. Determination of within-tree variation of Kraft pulp yield using near-infrared spectroscopy. Appita J. 81: 229-236.

Schimleck L.R., Stürzenbecher R., Mora C., Jones P.D., and Daniels R.F., 2005. Comparison of Pinus taeda L. wood property calibrations 
based on NIR spectra from the radial-longitudinal and radialtransverse faces of wooden strips. Holzforschung 59: 214-218.

Schimleck L.R., Sussenbach E., Leaf G., Jones P.D., and Huang C.L., 2007. Microfibril angle prediction of Pinus taeda wood samples based on tangential face NIR spectra. IAWA J. 28: 1-12.

Simatupang H.M. and Yamamoto K., 2000. Properties of teakwood (Tectona grandis L.f) and Mahogany (Swietenia macrophylla King) from manmade forest and influence on utilization. In: Hing Hon C., Matsumoto K. (Eds.). Proceeding of seminar on high value timber for plantation establishment. Conference Tawau, Sabah, Japan. JIRCAS. Report $N^{\circ} 16$, pp. 103-114.

Simpson W. and TenWold A., 1999. Physical properties and moisture relations of wood. In: Wood handbook - Wood as an engineering material, US Department of Agriculture, Forest Service, Forest Products Laboratory, $463 \mathrm{p}$.

Stamm A.J., 1971. Review of nine methods for determining the fiber saturation points of wood and wood products. Wood Sci. 4: 114-128.
Taylor A.M., Baek S.H., Jeong M.K. and Nix G., 2008. Wood shrinkage prediction using NIR spectroscopy. Wood Fiber Sci. 40: 301-307.

Trokenbrodt M. and Josue J., 1999. Wood properties and utilisation potential of plantation teak (Tectona grandis) in Malaysia: a critical review. J. Trop. For. Prod. 5: 58-70.

Tsuchikawa S., 2007. A review of recent near infrared research for wood and paper. Appl. Spectrosc. Rev. 42: 43-71.

Williams P.C. and Sobering D.C., 1993. Comparison of commercial near infrared transmittance and reflectance instruments for analysis of whole grains and seeds. J. Near Infrared Spectrosc. 1: 25-33.

Wright J.A., Birkett M.D., and Gambino M.J.T., 1990. Prediction of pulp yield and cellulose content from wood samples using near infrared reflectance spectroscopy. Tappi J. 73: 164-166.

Yamamoto K., Simatupang H.M., and Hashim R., 1998. Caoutchouc in teak wood (Tectona grandis L.f.): formation, location, influence on sunlight irradiation, hydrophobicity and decay resistance. Holz Roh Werkst. 56: 201-209. 